\title{
On numerical simulation of powder compaction process: powder transfer modelling and characterisation
}

\author{
J. C. Cante, J. Oliver, C. González, J. A. Calero \& F. Benítez
}

To cite this article: J. C. Cante, J. Oliver, C. González, J. A. Calero \& F. Benítez (2005) On numerical simulation of powder compaction process: powder transfer modelling and characterisation, Powder Metallurgy, 48:1, 85-92, DOI: 10.1179/003258905X37684

To link to this article: https://doi.org/10.1179/003258905X37684

曲 Published online: 19 Jul 2013.

Submit your article to this journal $\pi$

山 Article views: 36

Q View related articles ๔

4 Citing articles: 9 View citing articles 


\title{
On numerical simulation of powder compaction processes: powder transfer modelling and characterisation
}

\author{
J. C. Cante, J. Oliver, C. González, J. A. Calero and F. Benítez
}

A numerical model for the powder transfer stage in powder metallurgy cold compaction processes, and the corresponding material characterisation procedure, are proposed. They have been designed on the basis of the following requirements: robust and consistent computational mechanics ingredients, reliability of the obtained results for practical processes in powder metallurgy and industrial viability in the sense that characterisation of any mixture doesn't require either much effort or much time of the enduser. The starting point is a previously developed numerical model for powder compaction, formulated in terms of the large plastic deformation theory, which requires calibration of four parameters controlling the evolution of the yield surface. This calibration, which had been successfully carried out
in the past in a range of moderate to high densities, is
now extended to very low densities in order to make
numerical simulations able to deal with compadtion
processes involving relevant powder transfer stages.
To circumvent the difficulties inherent to direct
measurements of very low powder densities, a simple
apparatus, which allows studying the powder motion
in the chamber, has been designed to provide an

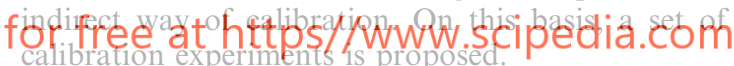

The proposed methodology appears to be simple and industrially viable. Although in the work it is applied to the specific constitutive model used by the authors, it also appears available for other families of constitutive models for powder compaction. As a relevant result, this would allow the same constitutive model to be used, via only the appropriated material characterisation, for simulation of densification in powder transfer stages as well as in pure compaction stages.

$\mathrm{PM} / 1092$

Dr Cante (juan.cante@upc.edu) is at the Technical University of Catalonia (UPC), Campus Terrassa, TR45, Cl. Colom, 11, 08222 Spain. Professor Oliver and $\mathrm{Mr}$ González are at the International Center for Numerical Methods in Engineering (CIMNE), Technical University of Catalonia (UPC), Campus Nord UPC, Edifici C1, Jordi Girona 1-3, 08034 Barcelona, Spain. Dr Calero and Mr Benitez are with AMES S.A., Crta Nal. 340 Km 1242 Pol. Ind. Les Fallulles, 08620 San Vicenc dels Horts, Spain. Manuscript received 23 June 2003; accepted 23 June 2004.

Keywords: Numerical Simulation, Powder Compaction, Transfer Modelling

(C) 2005 Institute of Materials, Minerals and Mining. Published by Maney on behalf of the Institute.

\section{INTRODUCTION}

During the last two decades, a number of numerical models to predict the mechanical behaviour of the powder during compaction processes ${ }^{1-10}$ have been proposed. Their mechanical (constitutive) ingredients are, in general, particularisations of the family of porous and frictional elasto-plastic material models, including one or more yield surfaces, with either associative or non-associative flow rules, and several (density dependent) parameters that control the size and shape of the yield surface.

As for the numerical strategy, the finite element method has been successfully applied to powder forming simulation $^{2,5-7,10-13}$ but essentially restricted to the pressing and ejection phases. In these cases a full die cavity, with the required amount of properly distributed powder of uniform density, is taken as the initial geometry for the simulation of

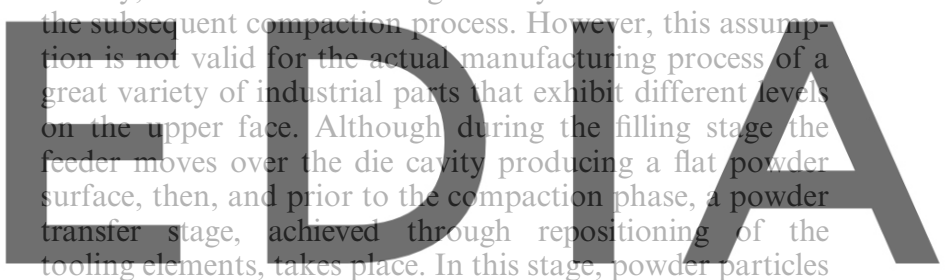

experience substantial motions, which can result in relevant

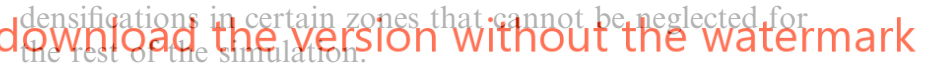

Friction among the powder grains, tooling kinematics and, occasionally, the applied forces are the main factors that can distort density distributions during powder transfer stages. In many cases, partially empty powder regions can appear that result in very low density zones after compaction, which, in turn, are responsible for mechanical defects in the final part. Removal or minimisation of these zones requires, among other actions, a proper definition of the tooling kinematics. Therefore, the powder transfer stage should be considered in any comprehensive numerical simulation tool aiming at helping the designer of the compaction process.

However, this transfer stage has been little analysed. The reasons are diverse: on one hand the difficulty to obtain reliable experimental results and, on the other, the important difficulties found when trying to simulate large motions of the powder with the numerical tools developed so far. From the experimental and numerical point of view, very relevant results in powder transfer can be found in Refs. 14 and 15. There, the use of the discrete element method (DEM) is proposed as an alternative to circumvent the intrinsic limitations of the classical finite element method when the phenomena involve large displacements and strains.

On the contrary, the present work focuses on a generalisation of the powder compaction model, initially described in Refs. 9-11, which is extended to include the powder transfer stage from a continuum point of view. Based on: some experimental results reported in the literature so 


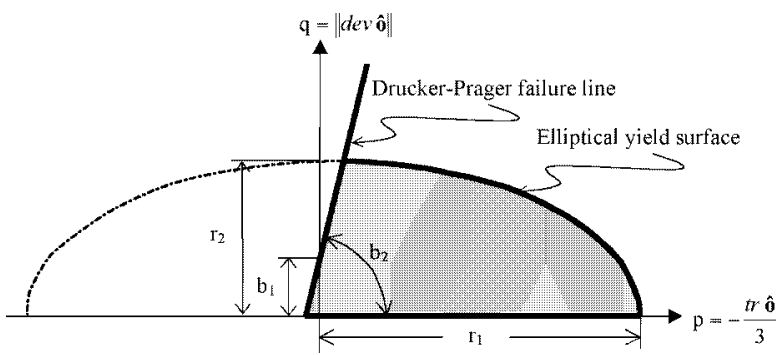

1 Yield surface: centred ellipse and Drucker-Prager line

far, ${ }^{13,14,16,17}$ a small number of parameters to be calibrated in the constitutive model and the computational efficiency of the resulting numerical tool, the authors propose in this work a multisurface frictionallike elasto-plastic constitutive model, formulated in terms of the large plastic deformations, in which the failure envelope is a Drucker-Prager surface and the cap is defined by means of a centred elliptical one. A non-associative flow rule is defined on the failure envelope whereas an associative one is defined for the ellinse. The evolution of these surfaces is controlled by means of four parameters depending on the density. The constitutive model is completed adding up the Young's modulus and the Poisson ratio whose evolution is defined in terms of the density. Friction between walls and powder is included through a Norton-Hoff type model that requires the calibration of one additional coefficient that depends on the velocity and density.

Calibration of the compaction model is carried out as follows: the two parameters defining the ellipse are calibrated through monitorin

flat cylindrical part (thus mi whereas the two parameters envelope are calibrated by ompression test and Brazilian e brittle character of green oefficients are calibrated on thin cy indrical specimens
vith a large aspect ratio, such that the effects of friction on powder densification are maximised. However, those tests cannot be performed for the region of low densities $4.0 \mathrm{~g} \mathrm{~cm}^{-3}$, for iron powder) and the correct determination of powder behaviour for that region is an open problem so far. In the remainder of this work, with the aim of improving the calibration at that range and keeping in mind the industrial application of the results, a new family of experiments at the low density region is proposed.

\section{CONSTITUTIVE MODEL}

The model is formulated in terms of the large plastic deformations and it is based on the results presented in Refs. 9-11 where a numerical model for the compaction stage was presented. There, one centred elliptic surface depending on two parameters was proposed. The extension presented here consists, essentially, of the reformulation of the yield surface, the plastic flow and its numerical implementation. The yield surface is extended to a multiple surface case adding up to the ellipse a new surface of the Drucker-Prager type (see Fig. 1). Then, the ellipse is devised to capture the material hardening during compaction, whereas the role of the Drucker-Prager surface is to control the material mechanical failure at high densities and to account for friction effects between grains at low densities.

The adopted kinematics is based on the multiplicative decomposition of the deformation gradient tensor $\mathbf{F}$ that is decomposed into its elastic and plastic counterparts, ${ }^{18}$ $\mathbf{F}=\mathbf{F}^{\mathrm{e}} \mathbf{F}^{\mathrm{p}}$ and, consequently, the strain tensor admits an additive decomposition into the elastic and plastic strains $\mathbf{e}=\mathbf{e}^{\mathrm{e}}+\mathbf{e}^{\mathrm{p}}$. The plastic (irrecoverable) strain $\mathbf{e}^{\mathrm{p}}$ is then interpreted as the loss of voids between grains during the compaction, and the elastic component $\mathbf{e}^{\mathrm{e}}$ comes from the (recoverable upon unloading) particle elastic deformation.

The elastic response is described in terms of an elastic energy deformation defined by means of a quadratic function of the elastic strains. From that, the Kirchhoff stress tensor can be written in a Hooke lawlike way in terms of the elastic strains $\mathbf{e}^{\mathrm{e}}=\mathbf{e}-\mathbf{e}^{\mathrm{p}}$

$$
\hat{\mathbf{o}}=\lambda \operatorname{tr}\left(\mathbf{e}^{\mathrm{e}}\right)+2 \mu\left(\mathbf{e}^{\mathrm{e}}\right)=\lambda \operatorname{tr}\left(\mathbf{e}-\mathbf{e}^{\mathrm{p}}\right)+2 \mu\left(\mathbf{e}-\mathbf{e}^{\mathrm{p}}\right)
$$

where $\mu$ and $\lambda$ are the classical Lamé constants.

The strength evolution of the material is controlled by means of the two following surfaces

$$
\begin{aligned}
& \Phi_{1}(\tau, \rho)=q^{2}+s_{2}^{2}(\rho) p^{2}-\left[s_{1}(\rho) s_{2}(\rho)\right]^{2} \leqslant 0 \\
& \Phi_{2}(\tau, \rho)=q+b_{1}(\rho) p-b_{2}(\rho) \leqslant 0 \quad .
\end{aligned}
$$

where $q=\|\operatorname{dev} \tau\|$ is the norm of the deviatoric part of $\hat{\mathbf{o}}$, $p=\frac{1}{3} \operatorname{tr} \tau$ is the mean stress and $\rho$ stands for the powder density. Functions $\Phi_{1}(\hat{\mathbf{o}}, \rho)=0$ and $\Phi_{2}(\hat{\mathbf{o}}, \rho)=0$ define, respectively, an ellipse and a straight line in the $p-q$ plane (see Fig. 1). Parameters $s_{1}$ and $s_{2}$ determine the size and shape of the ellipse in terms of the radii $r_{1}$ and $r_{2}$ as

$$
s_{1}(\rho)=r_{1}(\rho) s_{2}(\rho)=\frac{r_{2}(\rho)}{r_{1}(\rho)}
$$

Parameters $b_{1}(\rho)$ and $b_{2}(\rho)$ correspond, respectively, to the friction angle and cohesion of the Drucker-Prager failure envelope. Notice the dependence on the density $\rho$ of parameters $s_{1}, s_{2}, b_{1}, b_{2}$ and, therefore, of the shape and size of both surfaces in Fig. 1 .

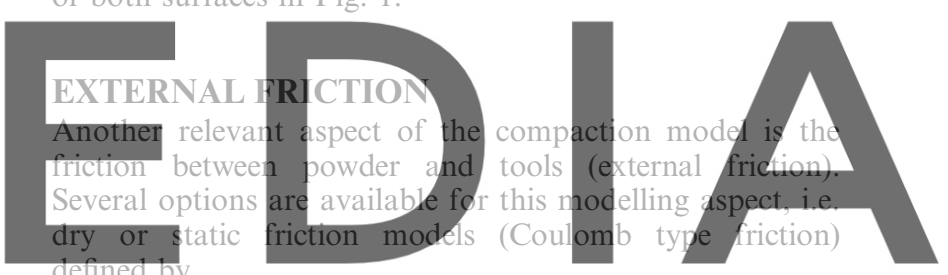

$\mathbf{t}_{\mathrm{T}}=\mu_{\mathrm{s}}(\rho) t_{\mathrm{N}}$

(4)

\section{download the version without the watermark} respectively, and $\mu_{\mathrm{s}}(\rho)$ is the (density dependent) friction coefficient, and also dynamic friction models (NorthonHoff type) given by

$$
\mathbf{t}_{\mathrm{T}}=\mu_{\mathrm{d}}(\rho, v) t_{\mathrm{N}}
$$

where the friction coefficient $\mu_{\mathrm{d}}(\rho, \mathrm{v})$ depends on both the density and the relative powder/tool tangential velocity $v$. Both families were implemented and extensively checked. It was observed that the dynamic friction model exhibits a more robust behaviour for numerical simulations and, therefore, it was chosen as the default friction model. Further details about this topic can be found in Refs. 10 and 11 .

\section{MATERIAL CHARACTERISATION}

The constitutive model described above involves several material properties that have to be evaluated for every powder mixture to be considered in the simulations. ${ }^{19}$ The procedure to determine the evolution of the material properties necessary for the model, and supplied to the material database of the simulation code shall be termed 'characterisation of the material'. One should impose on that procedure the following requirements: simplicity, in the sense that characterisation of any mixture does not require either much effort or much time to the enduser accuracy of the results (in appropriate balance with the first requirement) and consistency with the selected mathematical model. 


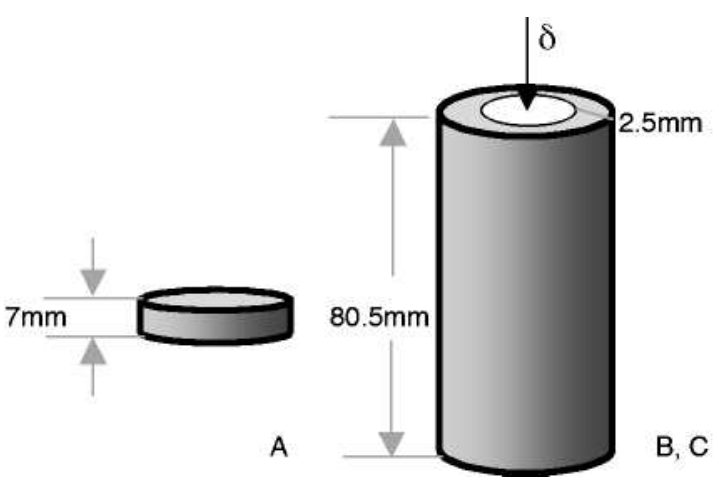

2 Specimens for material characterisation. Specimen A (slenderness height/radius $\approx 1$ ) and specimens $B, C$ (slenderness height/thickness $\approx 17-30$ )

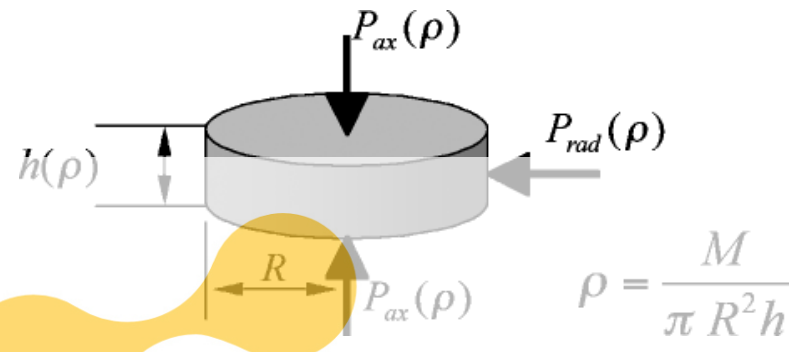

3 Slightly slender specimen

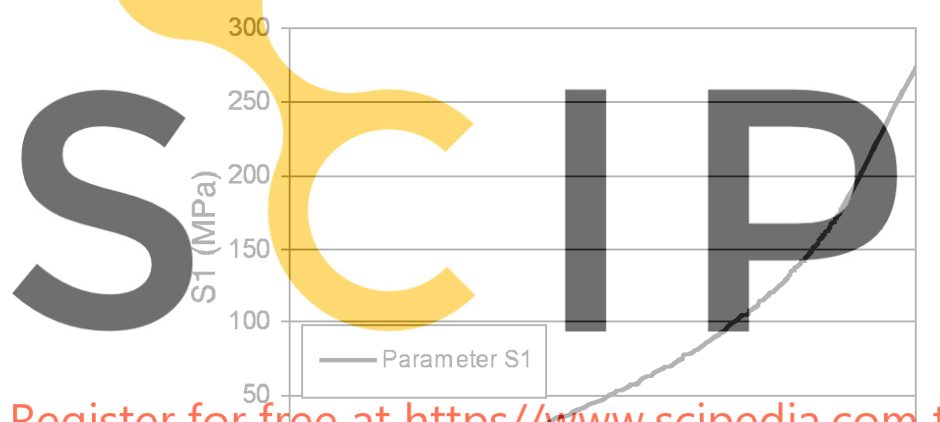

Register for free at https/fwww.scipedia.com
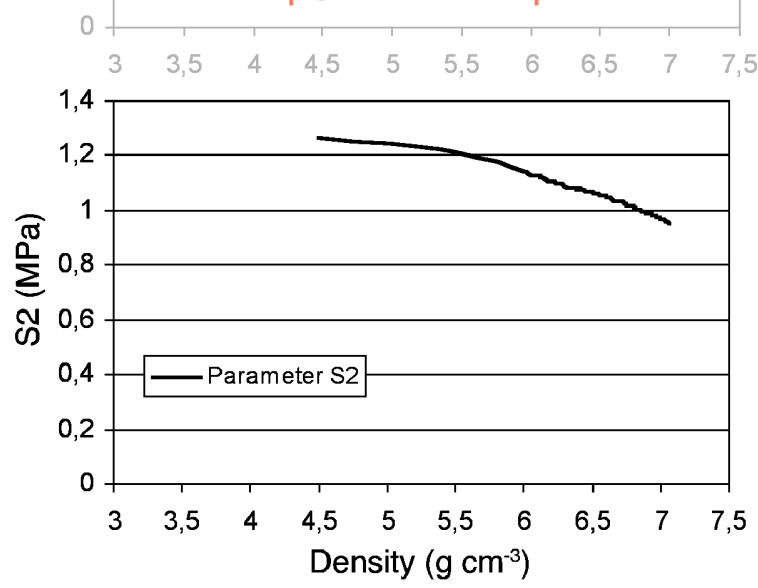

4 Evolution of parameters $s_{1}$ and $s_{2}$ in terms of density

Some of the material properties involved in the model above, have an immediate physical significance, and they can be extracted from standard laboratory tests, i.e. the elastic properties of the compact $\mu$ and $\lambda$ in equation (1). Also parameters $b_{1}$ and $b_{2}$, relative to the Drucker-Prager failure surface in equation $(2 b)$, can be obtained via well established fracture tests, such as compression and Brazilian disc tests, on green compacted parts. ${ }^{20}$

Nevertheless, there are other properties such as parameters $s_{1}(\rho), s_{2}(\rho)$ in equations (2a) and (3), and the friction
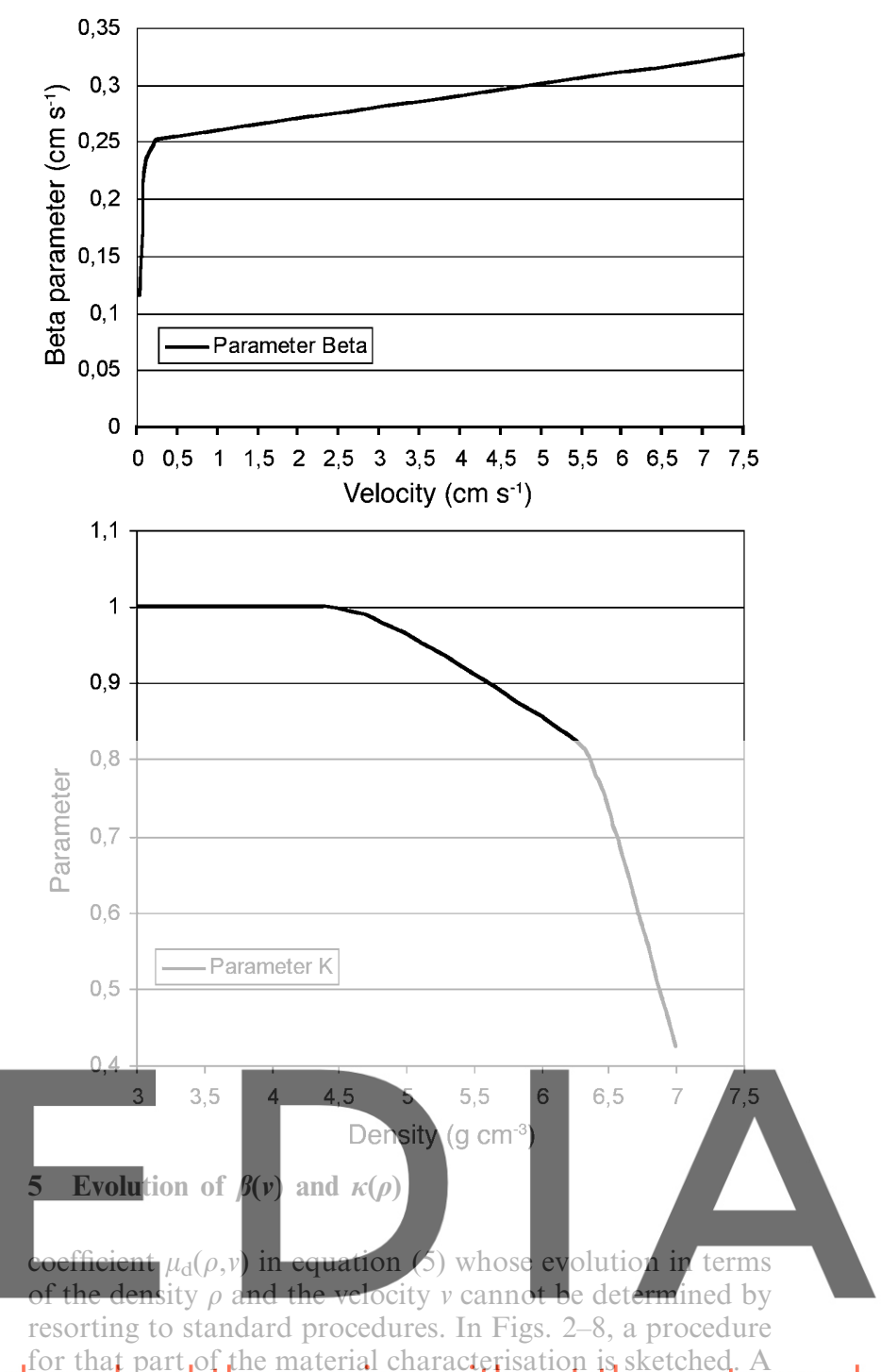

for that part of the material characterisation is sketched. A

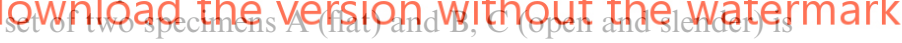
compacted via a uniaxial single effect procedure, in an experimental press (developed by AMES S.A.), which is equipped with monitoring and data capturing systems. Two load cells capture the evolution, along the compaction process, of the vertical upper and lower pressures on the specimen and, by resorting to a simple system of pins placed at fixed heights in the die, one or two (depending on the experiment) lateral pressures. In addition, the evolution of the height of the specimen is also registered. The corresponding digitalised histories are captured and

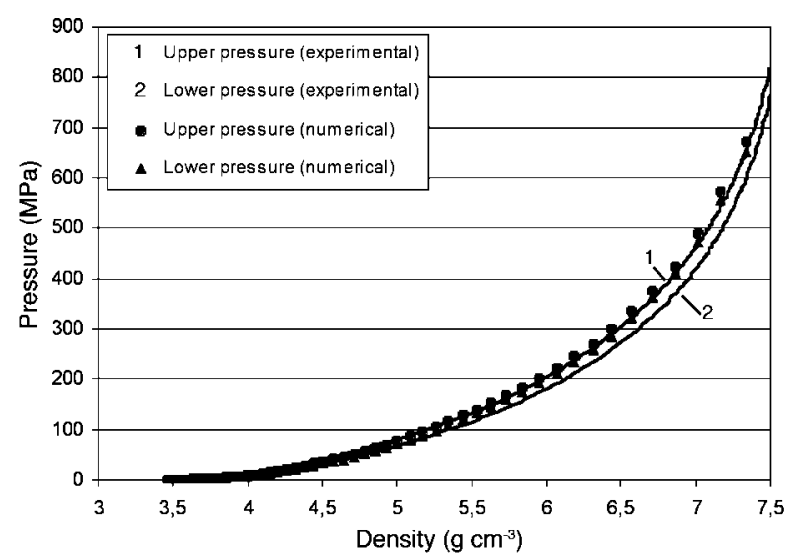

6 Uniaxial compaction of slightly slender part: specimen A 


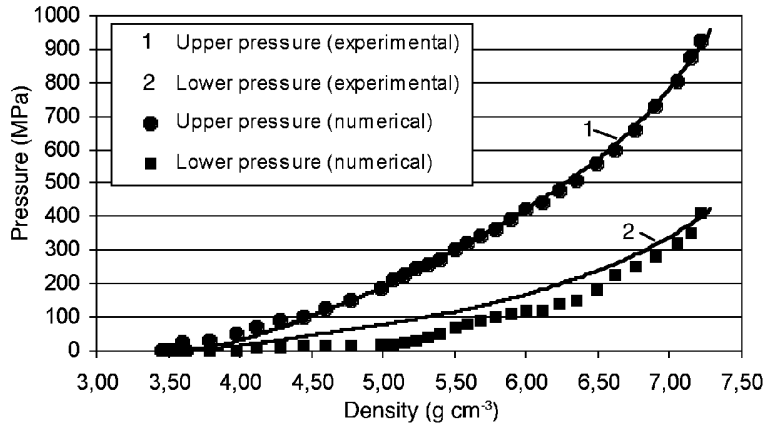

7 Uniaxial compaction of greatly slender part: specimen B $\left(\dot{\delta}=0.8 \mathrm{~mm} \mathrm{~s}^{-1}\right)$

recorded in experimental data files. All the specimens were produced using the same Distaloy AE $+0 \cdot 6 \% \mathrm{C}+0 \cdot 6 \%$ wax powder blend.

Results for specimen A, slightly slender (Fig. 3), are used to extract the compaction properties $s_{1}$ and $s_{2}$ assuming the following hypotheses.

H1. The stress and the strain fields are homogeneous and independent of the friction effects (due to the small aspect ratio of the specimen).

H2. The radial component of the plastic strain, $e_{\mathrm{p}}^{\mathrm{p}}$, is zero (emerging from the hypothesis that the elastic strains are negligible, $\mathrm{e}^{\mathrm{e}} \approx 0$, and that, for this particular geometry, the total radial strain $e_{\mathrm{rr}}$ is zero, so that $e_{\mathrm{rr}}^{\mathrm{p}}=e_{\mathrm{rr}}-e_{\mathrm{rr}}^{\mathrm{e}}=-e_{\mathrm{rr}}^{\mathrm{e}} \approx 0$ )

Under the assumptions above, the evolution equation of the plastic flow, restricted to the radial direction, can be

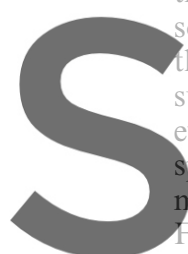
radial pressure $P_{\mathrm{rad}}$ in substitution into the yield fur becimen density $\rho$ is indiredtly hen height along the test and Then, for a given 1 mixture to be characterised, $P_{\operatorname{ax}}(\rho)$ and $P_{\operatorname{rad}}(\rho)$ can be computed. Finally, substitution of these data into those expressions provides

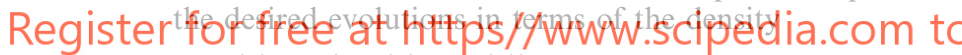
$s_{1}(\rho)=s_{1}\left(P_{\operatorname{ax}}(\rho), P_{\mathrm{rad}}(\rho)\right)$

$s_{2}(\rho)=s_{2}\left(P_{\operatorname{ax}}(\rho), P_{\operatorname{rad}}(\rho)\right)$

Typical curves $s_{1}-\rho$ and $s_{2}-\rho$ for iron powder obtained by means of that methodology, are shown in Fig. 4.

Once the material properties $s_{1}$ and $s_{2}$ have been determined from specimen $\mathrm{A}$, results obtained from testing the greatly slender specimen B, C (see Fig. 2) are used to extract the friction coefficient $\mu_{\mathrm{d}}(\rho, \mathrm{v})$. Geometrical features of specimens $\mathrm{B}$ and $\mathrm{C}$ are the same but the corresponding tests differ on the compaction velocity. Specimen B is compacted at the speed $\dot{\delta}=0.8 \mathrm{~mm} \mathrm{~s}^{-1}$ (low compaction speed) and specimen $\mathrm{C}$ is compacted at $\dot{\delta}=0.8 \mathrm{~mm} \mathrm{~s}^{-1}$ (high compaction speed). For these experiments, the following assumptions are made about the friction coefficient

H3. The friction coefficient can be split up into two terms

$$
\mu_{\mathrm{d}}(\rho, \mathrm{v})=\beta(\mathrm{v}) \kappa(\rho)
$$

which uncouple velocity and density dependences in terms of the factors $\beta(\mathrm{v})$ and $\kappa(\rho)$, respectively.

H4. The normal force $t_{\mathrm{N}}$, at the powder/die contact cylindrical surface, varies linearly in height.

H5. The relative velocity powder/die at the contact cylindrical surface has a parabolic variation in height from $v=0$ at the bottom of the specimen to $v=\dot{\delta}$ at the top.

Under those hypothesis, and imposing vertical equilibrium of forces, preliminary analytical solutions for $\beta(\mathrm{v})$

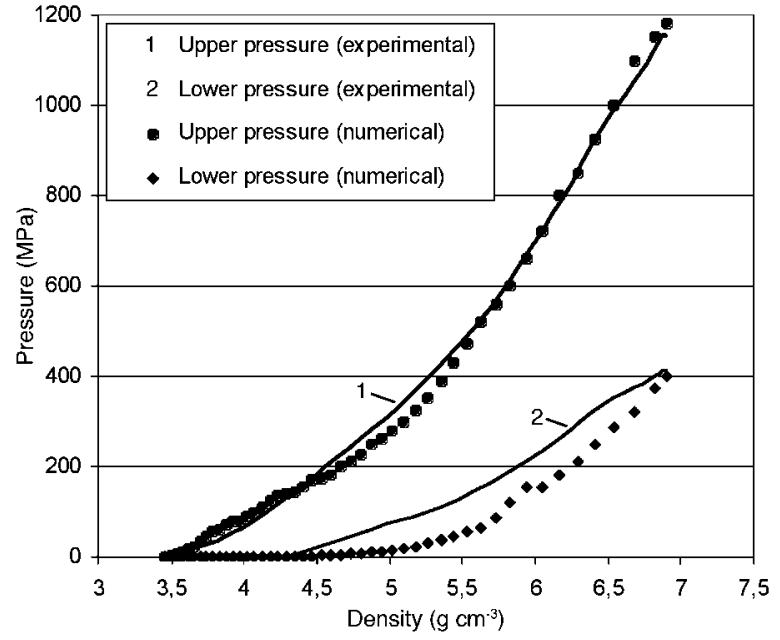

8 Uniaxial compaction of greatly slender part: specimen $\mathrm{C}\left(\dot{\delta}=8 \mathrm{~mm} \mathrm{~s}^{-1}\right)$

and $\kappa(\rho)$ can be obtained. The corresponding curves $\beta-$ and $\kappa-\rho$ are then corrected by comparison of numerical and experimental results in a trial and error procedure to achieve a satisfactory agreement. In Fig. 5, typical values of those curves, for an iron powder, are presented.

The values for parameters $s_{1}(\rho), s_{2}(\rho)$ and, $\mu_{\mathrm{d}}(\rho, \mathrm{v})$ obtained by means of those procedures are supposed to hold for the considered powder mixture under any loading conditions in the tested range of densities, thus characterising the material. In Figs. 6-8, a comparison between

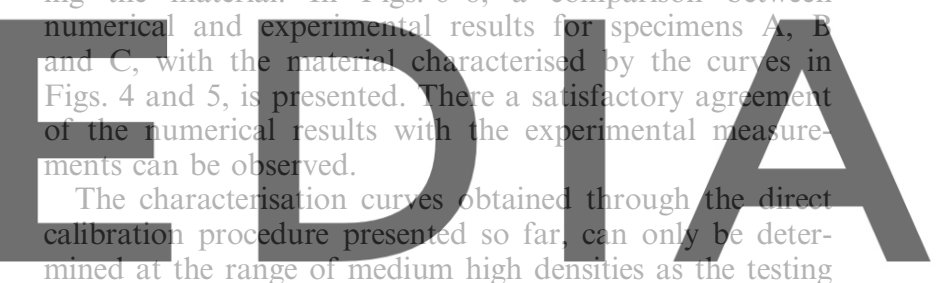

machine provides physically meaningful values (typically 0.6

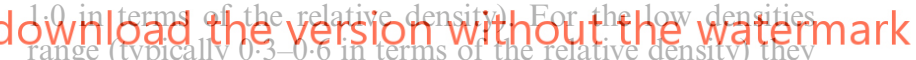
could be determined, as a first approximation, by simple extrapolation. This seems to be enough for capturing densification at pure compaction stages. However, preliminary numerical experiments showed that this was not enough as a significant amount of powder transfer takes place. Then, it turns out that, in the low density range, those material parameters should be determined via a different procedure, by resorting to indirect measuring of densification effects on some experimentally measurable physical property, i.e. the transfer ability of the powder. This motivated the experiment presented in the next section.

\section{Powder transfer experiment}

As stated above, a new set of experiments, to study the material behaviour during the powder transfer stage is required. According to this aim, AMES S.A. designed and built a simple piece of equipment to visualise and measure the powder transfer behaviour. Figure 9 displays a frontal view of this apparatus, where die, core and lower punch can be recognised. The apparatus is equipped with a feed handle that allows the user to move the lower punch to the required positions. In order to observe the internal process the front face of the apparatus is covered with a transparent material.

In Fig. 10 a typical initial chamber is presented, where the highlighted L shaped cavity is filled up with powder through the hole in the upper part of the die. The experiment consists of transferring powder, by means of 


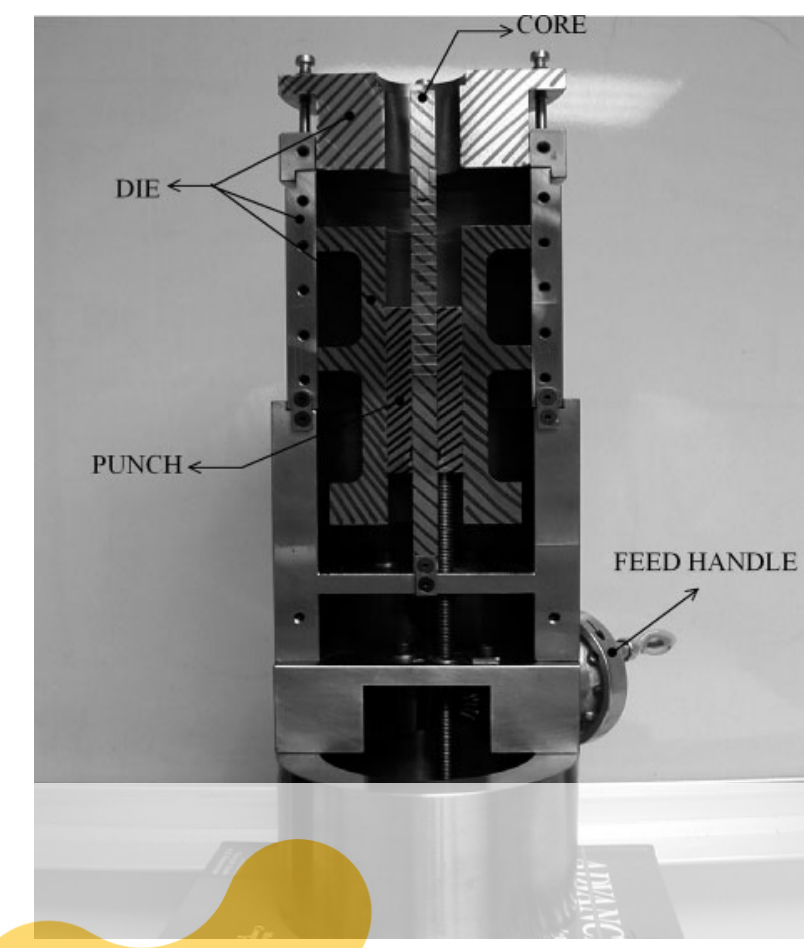

9 Specific apparatus to study powder transfer

the motion of the punch, from the $\mathrm{L}$ shaped initial configuration to the upper empty cavity.

In the absence of any type of friction (po should ex

powder/tooling frictions), one should expect the powder to

be transferred to the upper cavity without densification.
However, internal and external friction mechanisms lead to
local densification and only part of the powder volume lost

by the lower L shaped cavity is transferred to the enper one.
Thus, the amount of transferied powder is an indicator of the transfer capability of the mixture and provides an

indirect way of calibration for a model aiming at

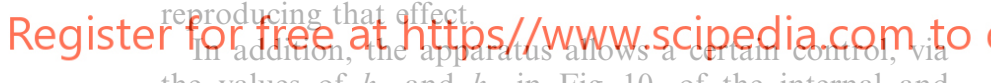
the values of $h_{\mathrm{a}}$ and $h_{\mathrm{b}}$ in Fig. 10, of the internal and external friction that is mobilised during the experiment

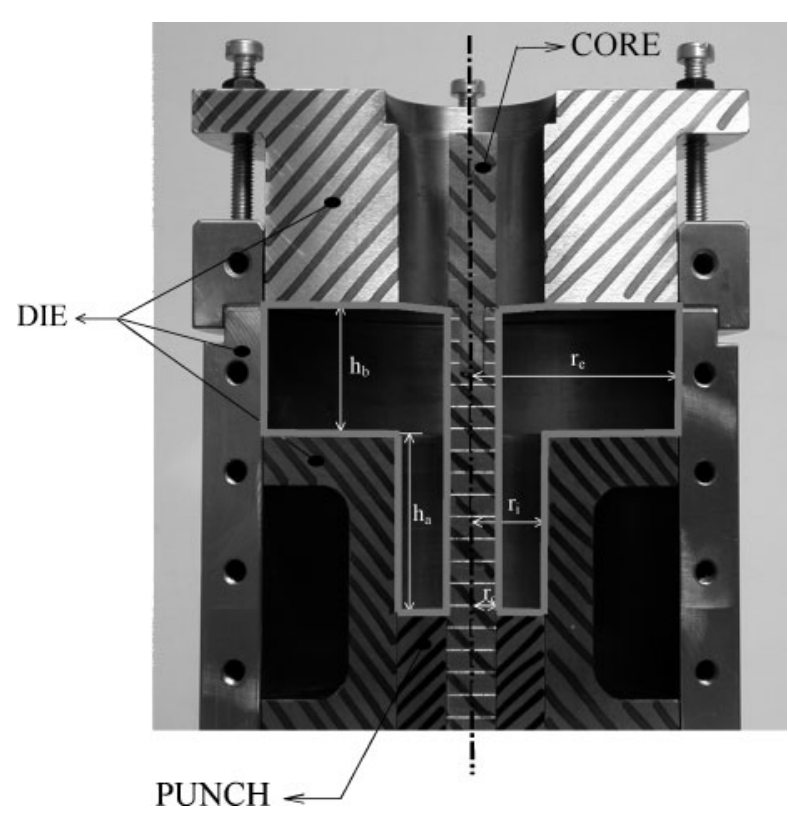

10 Frontal view of initial chamber: $r_{\mathrm{e}}=\mathbf{5 1} \mathrm{mm}$, $r_{\mathrm{i}}=18 \mathrm{~mm}, r_{\mathrm{c}}=6 \mathrm{~mm}$

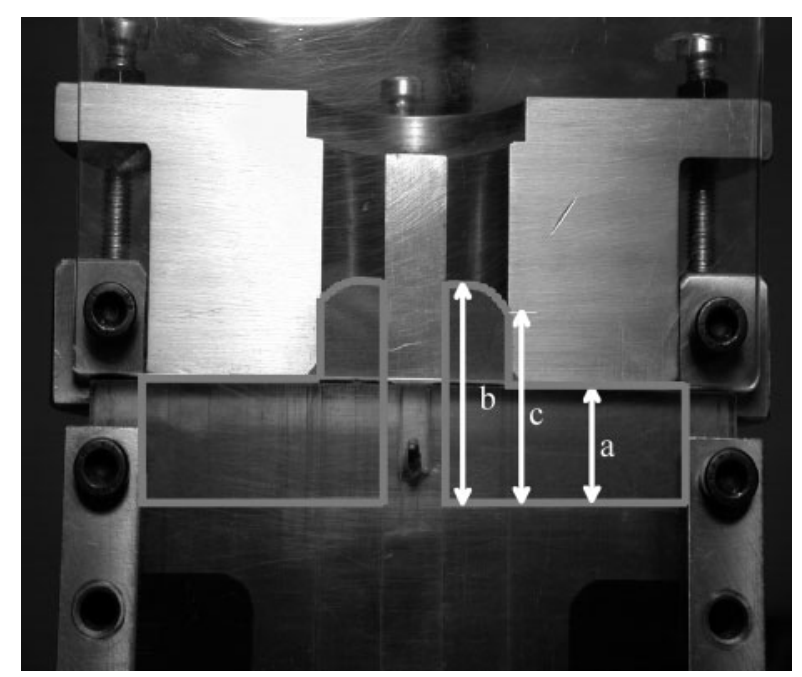

11 Experiment A: final deformation of powder after transfer stage. Lower punch displacement is $20 \mathrm{~mm}$ : a is $20 \mathrm{~mm}$; $b$ is $39 \mathrm{~mm}$; $c$ is $35 \mathrm{~mm}$

and, therefore, of the resulting amount of powder transfer. Experiments in Figs. 11 and 12 confirm that assertion: in experiment A the punch is initially placed such that $h_{\mathrm{a}}=h_{\mathrm{b}}=20 \mathrm{~mm}\left(h_{\mathrm{a}} / h_{\mathrm{b}}=1\right)$. Then, it is moved up to a final position such that $h_{\mathrm{a}}=0$ as shown in Fig. 11. There it can be checked that $95 \%$ of the initial volume of the lower powder column has been transferred to the final upper column $(b-a=19 \mathrm{~mm})$ and, consequently, little powder densifica-

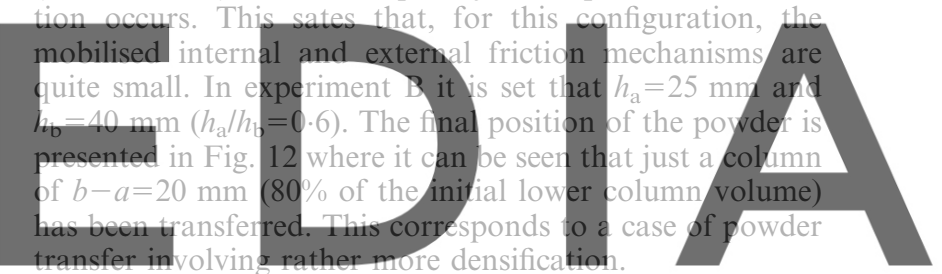

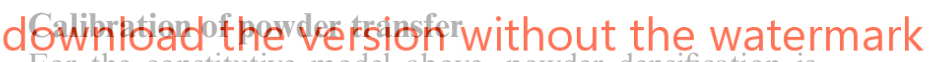
For the constitutive model above, powder densification is
closely related to the orientation of the normal to the elliptical yield surface, $\Phi_{1}$ in equation $(2 a)$, in the stress space (see Fig. 1), which in turn defines the plastic strain flow $\dot{\varepsilon}^{\mathrm{p}}$ for that associative plasticity model (see Fig. 13). The higher the hydrostatic component of $\dot{\boldsymbol{\varepsilon}}^{\mathrm{p}}$ (horizontal component figure) the more compressible is the powder, and the opposite holds for the deviatoric (vertical) component of $\dot{\varepsilon}^{\mathrm{p}}$. It then follows

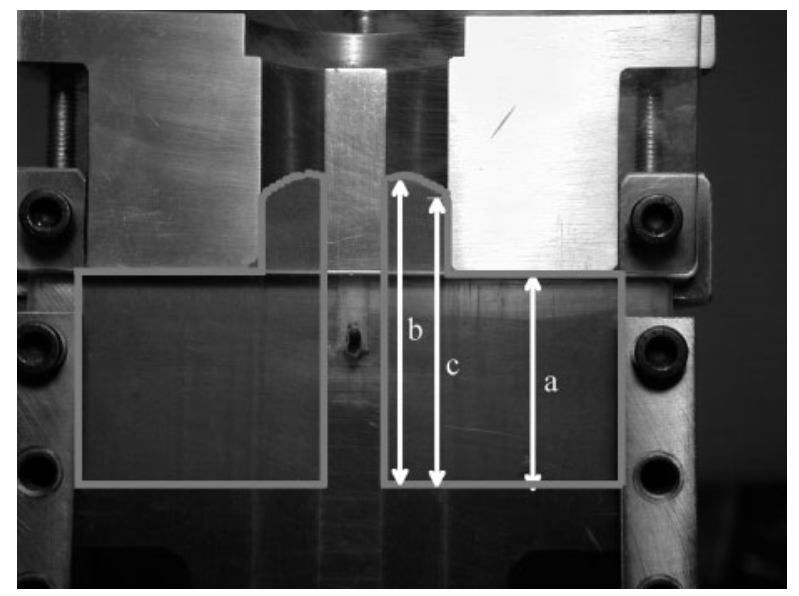

12 Experiment B: final position of powder after transfer stage. Lower punch displacement is $25 \mathrm{~mm}$ : a is $40 \mathrm{~mm}$; b is $60 \mathrm{~mm}$; c is $54 \mathrm{~mm}$ 

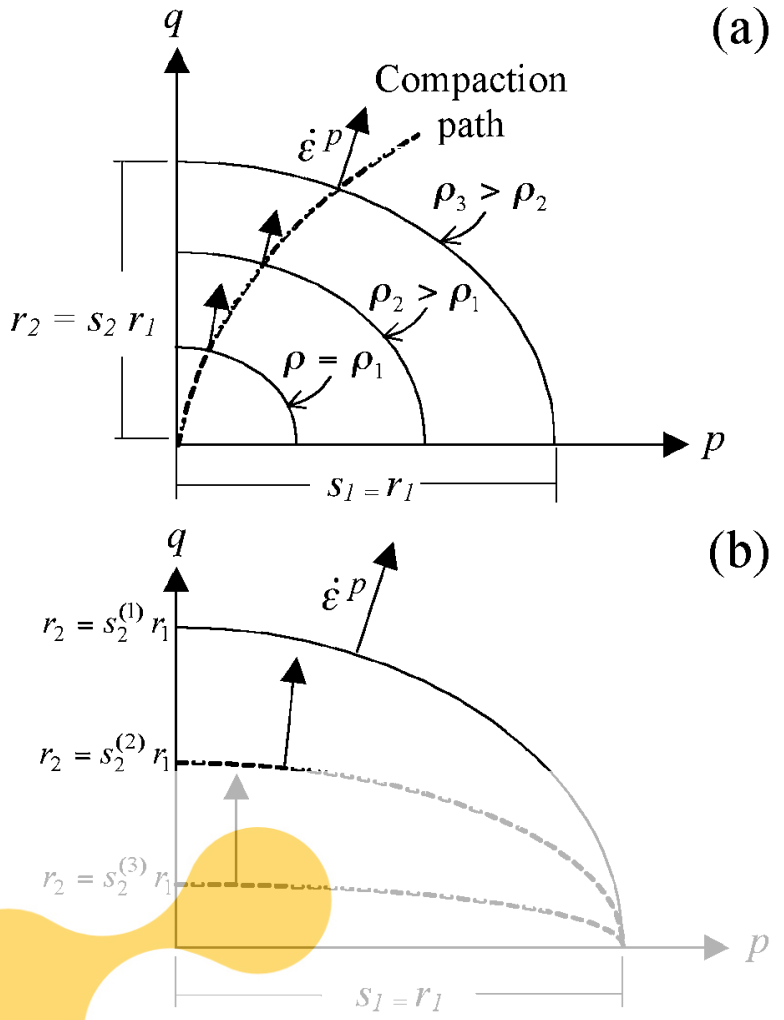

13 a typical yield surface shape and plastic flow vector for compaction process; $b$ yield surface and plastic flow vector for different values of shape factor $s_{2}$

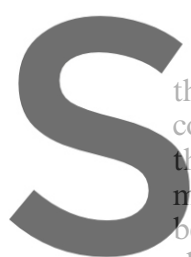

that, for a given path in the stress space during the compaction process (Fig. 13d), the flatter the yield surface hen the smaller is the resulting compaction (Fig. 13b) and nore powder transfer takes place. This is a crucial concept to e exploited for characterisation of the powder transfer: fla factor $s_{2}$ in equation (3), translate into more powder transfer

a)

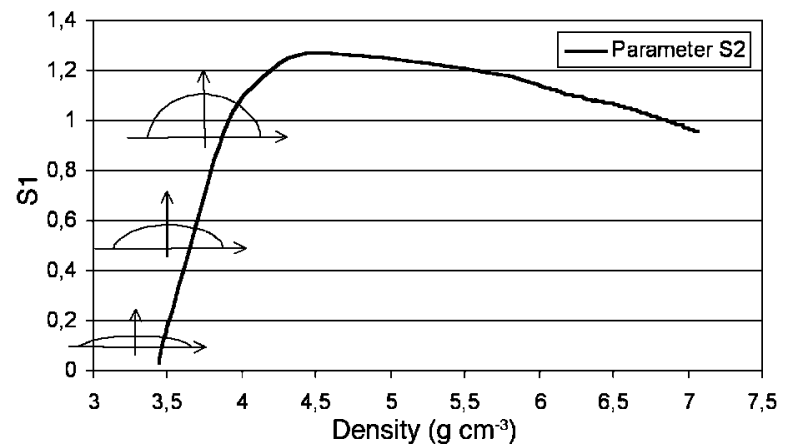

14 Typical $s_{2}-\rho$ curve for complete range of densities
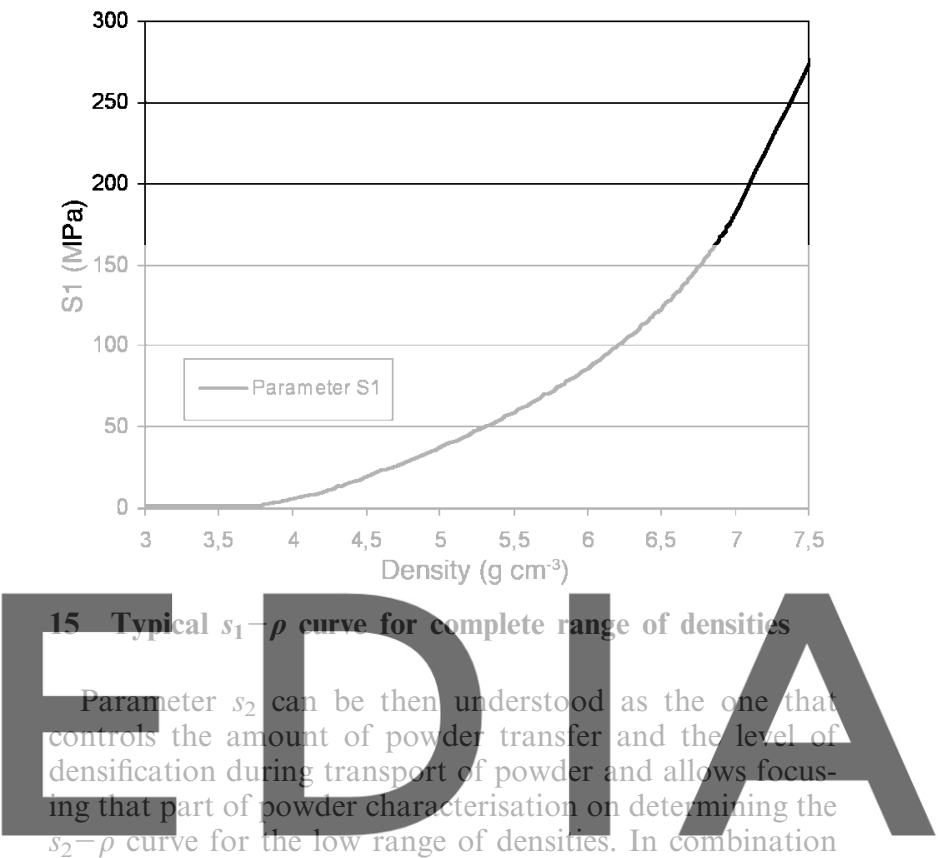
with the powder transfer experiments described above, trial

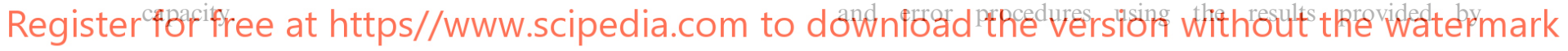
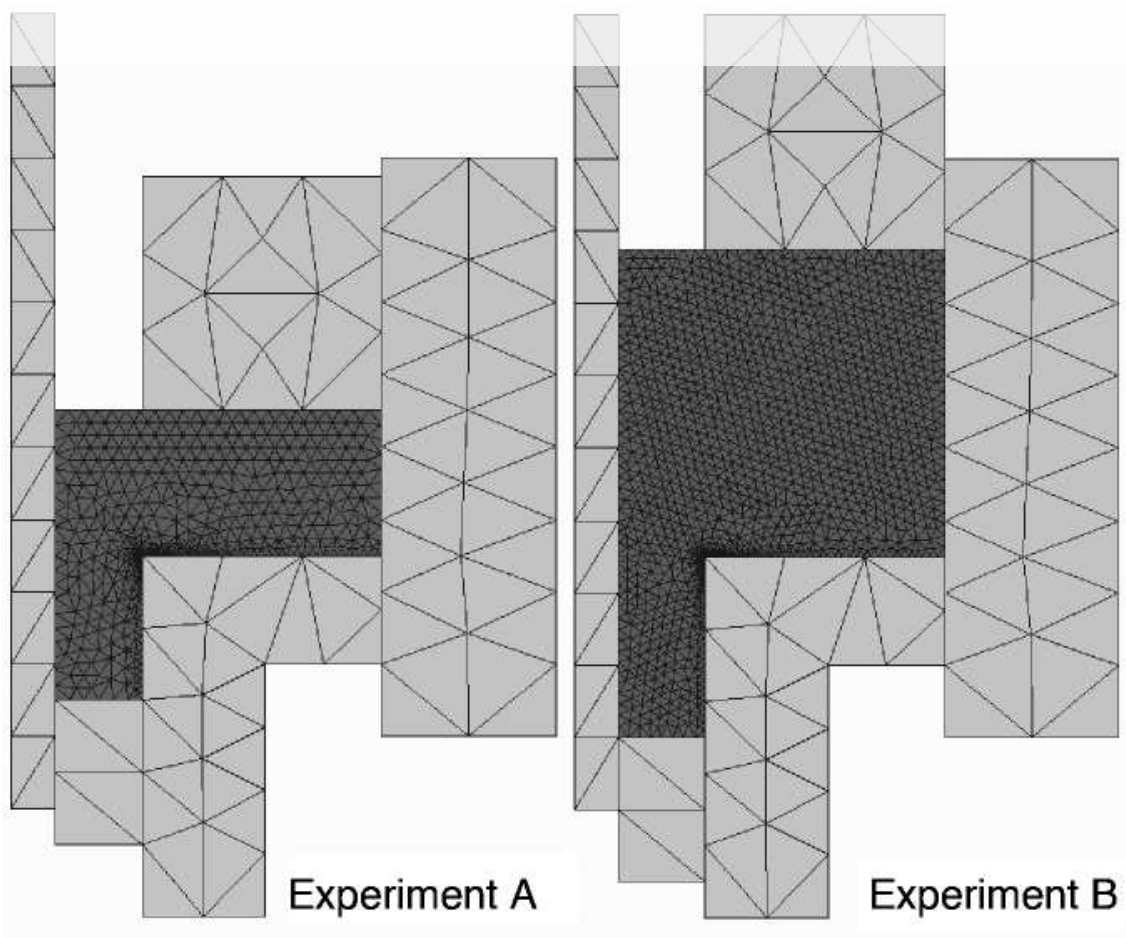

16 Numerical simulation of powder transfer experiments A and B. Initial geometries and finite element meshes 


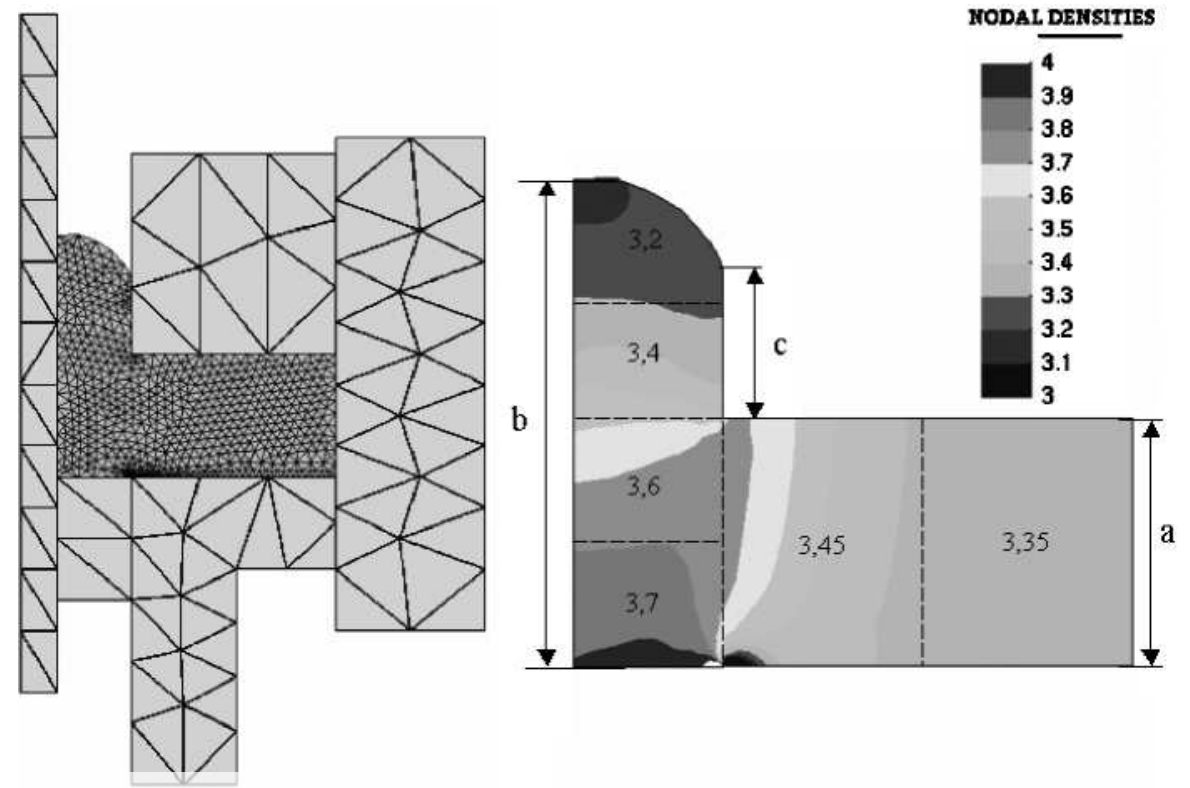

17 Numerical results for powder transfer experiment A in Fig. 11. Final powder position and density distribution: a is $40 \mathrm{~mm}$; b is $60 \mathrm{~mm}$; c is $54 \mathrm{~mm}$

numerical simulations for different guesses of that curve, allows the values of $s_{2}$ to be adjusted for that low range of densities. In Fig. 14, a typical resulting $s_{2}-\rho$ curve for the full range of densities, complementing the one obtained for medium high densities in Fig. 2, is presented. Finally, the curve $s_{1}-p$ for medium high densities in Eig. 15 is

the characterisation procedur

REPRESENTATIVE NUMERICAI IMULATIONS

For numerical modelling purposes. POWCOM, an implicit finite element code for simulation of powder compaction processes, equipped with large strain kinematics, contact friction algorithms and remeshing strategies, and GID, ${ }^{21}$ a customisable graphical pre/post processor, developed at the International Center for Numerical Methods in Engineering (CIMNE) have been used.

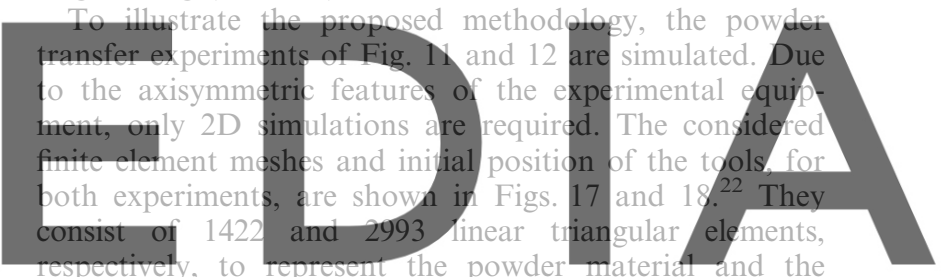

tools. The powder behaviour is simulated by means of the

Register for free at https//www.scipedia.com to download the version without the watermark
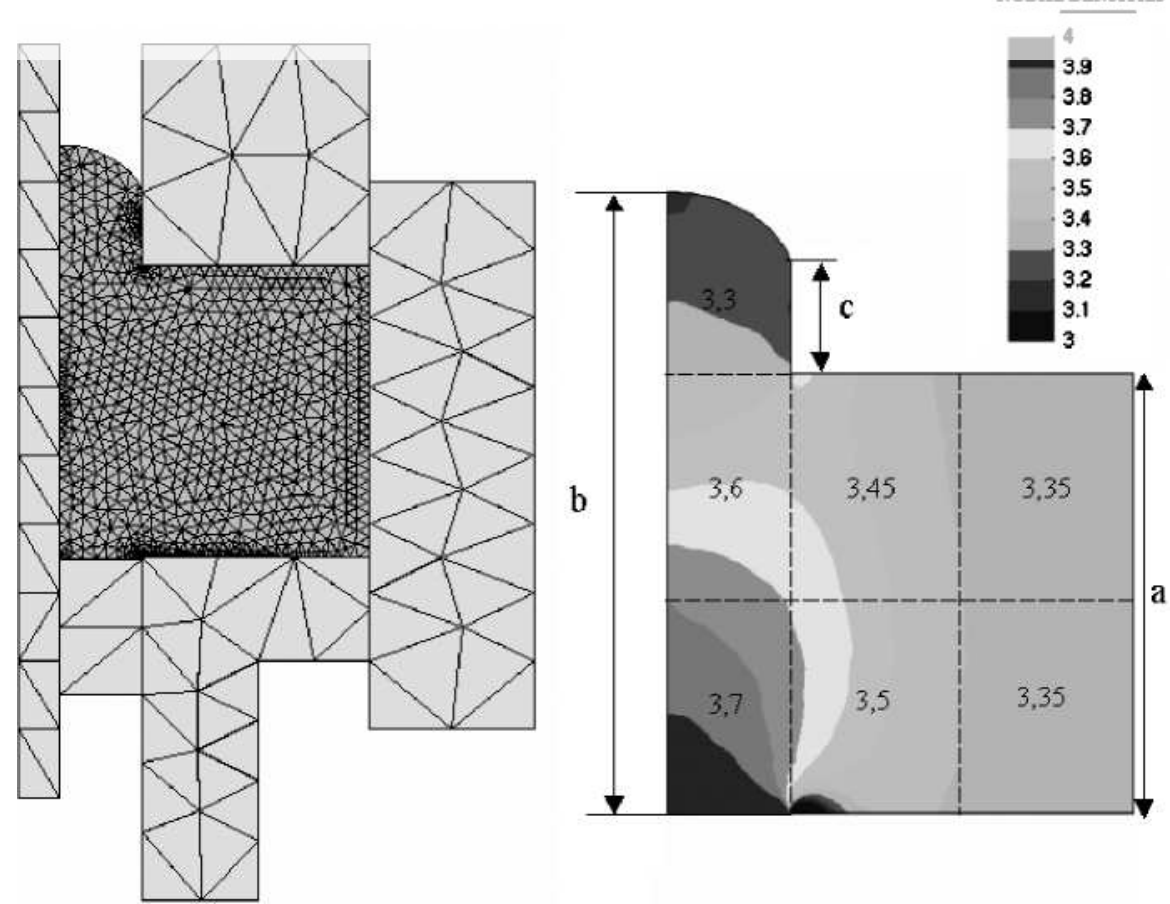

18 Numerical results for powder transfer experiment $B$ in Fig. 12. Final powder position and density distribution: a is $40 \mathrm{~mm}$; $b$ is $60 \mathrm{~mm}$; $c$ is $11 \mathrm{~mm}$ 
constitutive model described above, whereas the material parameters are adjusted according to the characterisation procedure also presented above. Other values are: apparent density, $3 \cdot 34 \mathrm{~g} \mathrm{~cm}^{-3}$, Young's modulus, $300 \mathrm{MPa}$, and $0 \cdot 3$ for the Poisson ratio. With no loss of generality, rigid tools are supposed. The considered time interval of the process is 3 s divided into 300 time steps.

In Figs. 17 and 18 simulation results corresponding to experiments A, in Fig. 11, and B, in Fig. 12, respectively, are presented. Comparisons in terms of the transferred powder column height and shape (values $b$ and $c$ in the figures) agree, as should be expected since material characterisation was made on that basis. More interestingly, it can be observed as the simulation provides values of non-negligible densifications and non-uniform final density distributions that could affect the simulation of a subsequent compaction process.

\section{CONCLUDING REMARKS}

Material characterisation of powder mixtures at low density ranges is still an open question. Direct measurements of mechanical pronerties and densification at those low densities place important experimental difficulties that cannot be easily overcome. On the other hand, numerical modelling of powder transfer in powder compaction processes requires proper characterisation of the powder densification at low densities.

Throughout the preceding sections, a methodology for calibration of powder transfer in compaction processes has been presented. Based on a simple apparatus, simple experiments provide measurable results in terms of powder transfer, which can be used for indirect material charactersation of powder mixtures at low density ranges for specific constitutive models. This complement classical material characterisation procedures ranges. Examples of application model have been provided. The proposed methodology appears to be simple and industrially viable. As it is applied to the specific constitutive model used by the authors, it allows direct determination of the specific parameter that defines the aspect ratio of the

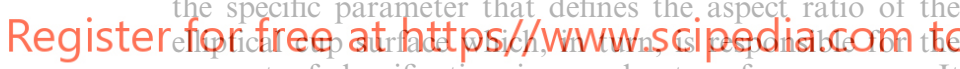
amount of densification in powder transfer processes. It seems that this methodology could also be applied to other families of constitutive modeis for powder compaction. As a relevant result, this would allow the same constitutive model to be used, via only the appropriated material characterisation, for simulation of densification in powder transfer stages as well as in pure compaction stages.

\section{ACKNOWLEDGMENT}

The support of the Spanish 'Ministerio de Ciencia y Tecnología' (MCYT) under grants no.
MAT2000-0436 and DPI2001-2256-C02-02, is gratefully acknowledged.

\section{REFERENCES}

1. B. AREN and A. NILSSON: Powder Metall., 1987, 30, 8796.

2. S. BROWN and G. WEBER: 'A constitutive model for the compaction of metal powders', Department of Materials Science and Engineering, MIT, Cambridge, MA, 1988.

3. D. T. GETHIN, and R. W. LEWIS: 'PM94: world congress on powder metallurgy'; 1994, Les Ulis Les Editions de Physique.

4. R. RANSING, I. CAMERON, N. LAVERY, A. KHOEI, R. LEWIS and D. GETHIN: Proc. Int. Workshop on 'Modelling of metal powder forming processes', Grenoble, France, July 1997, LGPM2, L3S, CEA/CERAM.

5. A. K. ARIFFIN, D. T. GETHIN and R. W. LEWIS: Powder Metall., 1998, 41, (3), 189-197.

6. A. R KHOEI and R. W. LEWIS: Int. J. Numer. Method. Eng., 1999, 45, 801-820.

7. W. A. M. BREKELMANS, J. D. JANSSEN, A. A. F. VAN DE VEN and G. DE WITH: Int. J. Num. Method. Eng., 1991, 31, 509-524.

8. T. NAKAGAWA and M. SATO: 'PM92: world congress on powder metallurgy', Vol. 2; 1992, London, Institute of Metals.

9. J. C. CANTE: 'Simulación numérica de procesos de compactación de pulvimateriales', PhD thesis, UPC, Spain, 1995.

10. J. Oliver, S. Oller and J. C. CANTE: Int. J. Solid. Struct., 1996, 33, 3161-3178.

11. R.WAYLER: 'Simulación numérica de procesos de compactación y extrusión de materiales pulverulentos', $\mathrm{PhD}$ thesis, UPC, Spain, 2000

12. PM MODNET COMPUTER MODELling Group: Powder Metall, 1999, 42, (4), 301-311.

13. PM MODNET RESEARCH GROUP: Powder Metall., 2002, 45, 335344.

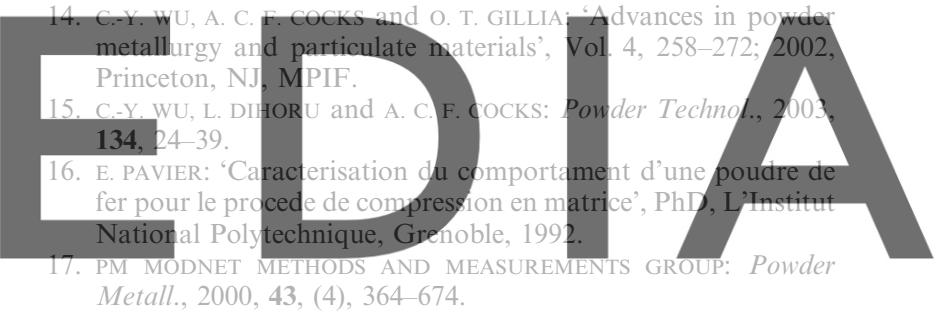

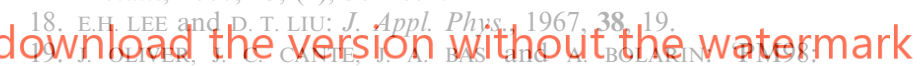
world congress on powder metallurgy'; 1998, Shrewsbury, EPMA.

20. P. DOREMUS, F. TOUSSAINT and O. ALVAIN: in 'Recent developments in computer modelling of powder metallurgy processes', NATO Advanced Research Workshop, Series III: Computer and Systems Science, (eds. A. Zavaliangos and A. Laptev), Vol. 176, 29-41; 2001, Amsterdam, IOS press.

21. GID: 'The customisable pre- and post-processor', International Center for Numerical Methods in Engineering (CIMNE), http://www.cimne.upc.es, 2003

22. P. BREWIN, P. DOREMUS, D. T. GETHIN, P. SKOGLUND, J. H. TWEED and H. WIEDEMANN: 'PM2000: world congress on powder metallurgy'; 2000, Kyoto, JPMA. 